\title{
A MEDIAÇÃO DIDÁTICA NA APRENDIZAGEM: A Construção do Conhecimento Geográfico
}

\author{
Izabella Peracini Bento ${ }^{1}$
}

\section{RESUMO}

Este artigo busca atender, especificamente, a dois objetivos: compreender o conceito de mediação na teoria histórico-cultural e destacar a importância da mediação didática para a aprendizagem geográfica. Este trabalho fundamenta-se na Teoria Histórico-Cultural e tem por objetivo utilizar como referência básica um de seus precursores, o professor e pesquisador bielo-russo Lev Semionovitch Vigotski (1896-1934). A perspectiva vigotskiana e seus desdobramentos para o campo educacional configuram-se como um essencial postulado teórico, principalmente no que se refere a quatro importantes contribuições desse estudo: a mediação, sobretudo a didática; a internalização; a formação de conceitos e as funções psíquicas superiores. Com base na reflexão que introduz este artigo, o presente estudo tem como finalidade desenvolver uma discussão, prioritariamente, acerca de um dos conceitos que envolvem um método e um caminho metodológico a se seguir no ensino - a mediação - à luz da perspectiva teórica vigotskiana. Cabe, assim, indagar: Como a mediação do professor propicia a atividade cognitiva do aluno, a partir de um encaminhamento metodológico?

Palavras-chave: mediação didática; construção do conhecimento; geografia; teoria histórico-cultural.

\section{DIDACTIC MEDIATION IN LEARNING: THE CONSTRUCTION OF THE GEOGRAPHICAL KNOWLEDGE}

\section{ABSTRACT}

This article seeks to meet specifically the two objectives: to understand the concept of mediation in the historical-cultural theory; to highlight the importance of didactic mediation for geographic learning. This work is based on the Historical-Cultural Theory and aims to use as a basic reference one of its precursors, the Belarusian professor and researcher Lev Semionovitch Vigotski (1896-1934). The Vygotskian perspective and its impact on the educational field are configured as an essential theoretical postulate, especially with regard to four major contributions of this study: the mediation, especially the didactic; internalization; concept formation and higher psychic functions. Based on the reflection that this article introduces, the present study aims to develop a discussion, primarily, about one of the concepts that involve a method and a methodological path to be followed in teaching - mediation -, in the light of the Vigotskian theoretical perspective. Thus, it is worth asking: how does the mediation of the teacher promote the student's cognitive activity, based on a methodological approach?

Keywords: didactic mediation; knowledge construction; geography; cultural historical theory. 


\section{INTRODUÇÃO}

Com o objetivo de refletir sobre a mediação didática na construção do conhecimento geográfico, este estudo promove um diálogo que situa o aluno, na condição de sujeito historicamente constituído, no contexto socioinstitucional da escola. Parte-se do pressuposto de que os conteúdos não possuem significados em si mesmos; de que aprender, construir conhecimento, é uma atividade cognitiva do aluno; de que existe uma relação entre a didática e a epistemologia das disciplinas; de que ensinar conteúdo não é o bastante, é preciso ensinar a pensar, a construir conhecimento, é preciso considerar a epistemologia da ciência, seus métodos de investigação e o seu desenvolvimento histórico. O caminho epistemológico percorrido neste trabalho provém do entendimento de que o aluno é o sujeito ativo e central no processo do conhecimento, portanto no processo de ensino e aprendizagem. Este artigo busca atender, especificamente, a dois objetivos: compreender o conceito de mediação na teoria histórico-cultural e destacar a importância da mediação didática para a aprendizagem geográfica.

Procura-se, assim, realizar uma discussão que vá ao encontro de uma concepção de ensino que está sendo compartilhada por vários pesquisadores da área do ensino de Geografia, que buscam nessa teoria uma base teórica e metodológica para suas discussões. Para isso, a trajetória de Libâneo e Freitas (2006), e de Libâneo (2009a, 2009b, 2012) na análise e compreensão desta corrente teórico-filosófica viabiliza um maior aprofundamento para sua compreensão. Na Teoria Histórico-Cultural, a aprendizagem é resultado de uma estreita relação entre fatores externos e internos, tendo como referência a internalização de signos culturais convertidos em ações mentais dos sujeitos. Essa concepção teórica tem em sua base uma importante premissa, em que é destacado o papel da atividade humana, construído social, histórica e coletivamente na formação das funções mentais superiores. Isso ressalta o caráter de mediação cultural no processo de conhecimento, pois é pela atividade individual de aprendizagem que os indivíduos se apropriam ativamente da experiência social, cultural e histórica da humanidade.

Em suma, este trabalho fundamenta-se na Teoria Histórico-Cultural e tem por objetivo utilizar como referência básica um de seus precursores, o professor e pesquisador bielo-russo Lev Semionovitch Vigotski (1896-1934), não deixando de dar a devida importância a seus colaboradores. A perspectiva vigotskiana e seus desdobramentos para o campo educacional se configuram como um essencial postulado teórico, principalmente no que se refere a quatro importantes contribuições desse estudo: a mediação, sobretudo a didática; a internalização; a formação de conceitos e as funções psíquicas superiores.

\section{A MEDIAÇÃO DIDÁTICA NA TEORIA HISTÓRICO-CULTURAL}

Com base na reflexão que introduz este artigo, o presente estudo tem como finalidade desenvolver uma discussão, prioritariamente, acerca de um dos conceitos que envolvem um método e um caminho metodológico a se seguir no ensino - a mediação - à luz da perspectiva teórica vigotskiana. Cabe, assim, indagar: como a mediação do professor propicia a atividade cognitiva do aluno, a partir de um encaminhamento metodológico? 
Com a finalidade de responder a essa questão, buscam-se elementos na Teoria Histórico-Cultural para se pensar a mediação didática com base nos processos de internalização, formação de conceitos e o desenvolvimento psicológico e mental.

A mediação, um princípio basilar da Teoria Histórico-Cultural, perpassa todos os estudos de Vigotski. Na concepção do autor, os sujeitos não agem de forma direta e imediata no mundo físico e social, mas sim de forma indireta ou mediada por signos e instrumentos. A mediação é compreendida pela marca da consciência humana. $\mathrm{O}$ instrumento usado pelo homem é um objeto social, é considerado e apropriado pelos sujeitos para além de suas características físicas. O homem fabrica e planeja sua utilização para uma atividade produtiva. A habilidade de produzir um signo, introduzindo recursos psicológicos auxiliares, marca o comportamento humano e a cultura. A forma elementar do comportamento humano pautava-se na fórmula E-R (Estímulo-Resposta), mas, segundo Vigotksi, essa fórmula requer um elo intermediário entre o estímulo e a resposta, por exemplo, a memória, que funcionaria como um signo para a recordação.

O signo e o instrumento diferenciam-se em sua função mediadora. Os instrumentos são externamente orientados para o controle do mundo físico, levando a transformações objetais. Os signos são orientados internamente, para a comunicação e o controle e domínio do comportamento. Como exemplos de instrumentos podem ser citados desde uma vassoura até os artefatos mais complexos usados pelo homem no dia a dia. Os signos, por sua vez, estão relacionados aos números, palavras, símbolos, escrita, esquemas, etc. A utilização de instrumentos e signos pelos sujeitos não se limita a necessidades pessoais apenas, afinal, suas funções mediadoras estão ligadas a experiências anteriores, construídas culturalmente. As representações da realidade, ao longo da evolução humana, foram organizadas em sistemas simbólicos, ou seja, os signos são compartilhados por um conjunto de sujeitos pertencentes a determinado grupo social, com a linguagem constituindo o sistema simbólico básico de todos os grupos humanos.

Os processos de mediação e internalização possuem forte relação entre si. A internalização pode ser entendida como uma reconstrução interna, intrasubjetiva, de uma operação externa com objetos, ou seja, ocorre de uma atividade externa para uma atividade interna e de um processo interpessoal para um processo intrapessoal. Não se trata de um processo de transferência, e sim de um processo criador de consciência. É nesse sentido que um dos aportes teóricos para uma didática da Geografia, na atualidade, tem sido desenvolvido segundo uma concepção vigotskiana.

As orientações de Vigotski (2000) atestam que o sujeito nasce social e constrói sua individualidade/autonomia contando com uma série de mediações, como já mencionado. Concebe-se que a relação sujeito-objeto é dialética, contraditória e mediada, mediada no sentido de estabelecer o processo que promove a relação do homem com o mundo e outros homens. É nesse sentido que o professor pode ser considerado um mediador, na relação entre sujeito e objeto, ou melhor, entre aluno e conhecimento. 0 professor medeia a relação do aluno com o conteúdo. Ele trabalha com os conteúdos para ajudar os alunos a desenvolverem capacidades cognitivas, a aprenderem a pensar, 
e a pensar por si mesmos. Existe uma importância crucial do "outro" no processo de ensino-aprendizagem. Esse processo é coletivo, e o resultado é subjetivo, ainda que a apropriação seja individual.

Um dos conceitos básicos para o melhor entendimento da teoria da mediação é o conceito de "internalização", referido anteriormente. Segundo esse conceito, existe um caminho de ida e volta entre o "inter" (situações socioculturais) e o "intra" (internalização regulada pela consciência), em que funções sociais se convertem em funções pessoais e ocorre uma reconstrução interna do significado com geração de sentido.

Vale ressaltar, de acordo com a interpretação de Libâneo (2009a, 2009b, 2012) sobre a obra de Vigotski, que existem diferenças entre os processos de mediação. A mediação cognitiva é aquela que alimenta dispositivos internos que cada indivíduo possui (conhecimento, prática, vivência) para se apropriar da realidade externa; e a mediação didática é a "mediação da mediação cognitiva", ou seja, trata-se de fenômeno que intervém nos processos mentais dos alunos. No caso do professor, a sua mediação didática consiste em propiciar a atividade cognitiva do aluno, a partir de um encaminhamento metodológico do processo de ensino e aprendizagem. Advém desse processo a necessidade de o professor intervir nos motivos dos alunos, estabelecendo, assim, elos entre o conhecimento e as ações mentais dos estudantes e proporcionando uma possível construção/formação de conceitos. Dessa forma, o aprendiz passa a ter o domínio do conteúdo, mediante modos de operar métodos/procedimentos. O trabalho com determinado conteúdo permite, por meio da generalização, a aplicação em sua realidade prática.

A generalização pode ser compreendida, como assinala Libâneo (2009a, 2009b), no aprendizado de um conteúdo. Ou seja, o sujeito adquire os métodos e estratégias cognitivas gerais que são próprios de um conteúdo e converte-os em procedimentos mentais para análise e resolução de problemas e situações concretas da vida prática. O pensamento teórico desenvolve-se, portanto, no aluno pela formação de conceitos e pelos domínios dos procedimentos lógicos do pensamento. Este, pelo seu caráter generalizador, permite sua aplicação em vários âmbitos da aprendizagem. Na concepção de Vigotski (2000, 2007, 2010), os meios social e cultural ocupam espaço significativo para o entendimento da participação do indivíduo em seu processo de aprendizagem. Para isso, o autor estabelece a noção de "estruturação das funções psíquicas superiores".

Vale assinalar que esse princípio se colocava na contramão do pensamento da época, que propunha a análise de como o meio social age no indivíduo, criando nele funções superiores de origem essencialmente social. Com essa afirmação, Vigotski contrapõe-se a Piaget, por conceber que o desenvolvimento segue não no sentido da socialização, mas no da conversão das relações sociais em funções mentais. O problema das funções psíquicas superiores constitui o núcleo central do sistema de Vigotski (2000, 2007, 2010), com base no pensamento histórico-dialético.

Para a compreensão do sistema de ideias apresentado por Vigotski é fundamental explicitar seu entendimento sobre o desenvolvimento das funções psíquicas superiores, ou seja, a atividade simbólica composta por suas formas exteriores (linguagem, leitura, escrita, etc.) e interiores (atenção, memória, pensamento). 
$\mathrm{Na}$ base das funções psíquicas superiores situam-se a atividade laboral e a atividade mediadora do homem, incluindo o uso de instrumentos e signos em sua ação sobre a realidade e sobre si mesmo. As formas e ações sociais de atuação são assimiladas e transferidas para si próprio. Desse modo, todas essas formas de conduta, signos e instrumentos são produtos do desenvolvimento da cultura humana criada pelo próprio homem. Vigotski (2000, 2007, 2010) considerou como núcleo central a esses produtos, como mecanismo determinante em todas as formas de atividade do homem, a linguagem e seus significados verbais. A essência desse processo reside em considerar o externo como social. Assim, qualquer função psíquica superior foi externa, porque foi social antes de ser interna. Antes de ser uma função psíquica propriamente dita, foi uma relação social entre pessoas. Para o autor, a internalização é uma propriedade essencial da aprendizagem. Sobre a aprendizagem como decorrência dos processos educativos, Vigotski (2010, p. 67) entende que "a educação se faz através da própria experiência do aluno, a qual é inteiramente determinada pelo meio e, nesse processo, o papel do mestre consiste em organizar e regular o meio".

Nesse sentido, Vigotski (2010) critica a perspectiva tradicional do ensino segundo a qual o professor ensina os conteúdos e o aluno "aprende" sem a garantia de que houve a internalização. E enfatiza que a garantia dessa internalização é decorrente da experiência do aluno, é o que se caracteriza como elemento básico da aprendizagem e permite-lhe construir significados do meio nesse processo de ensino-aprendizagem. Vigotski dá ênfase, também, ao importante papel do professor na mediação desse processo, e ao da escola como espaço capaz de promover aprendizagens diferentes dos demais processos educativos. As aprendizagens advindas do processo educativo escolar constituem uma das preocupações centrais do autor.

Associada à noção de função superior, a mediação é o processo que permitirá o trajeto das questões sociais à dimensão social e psicológica do indivíduo. Segundo Cavalcanti (2005, p. 188), esse processo é decorrente de dois aspectos básicos:

Primeiro é o percurso da internalização das formas culturais pelo indivíduo, que tem início em processos sociais e se transforma em processos internos, interiores do sujeito, ou seja, por meio da fala chega-se ao pensamento. $O$ segundo aspecto é o da criação da consciência pela internalização, ou seja, Vigotski alerta, como dizem seus estudiosos, que esse processo não é de uma transferência (ou cópia) dos conteúdos da realidade objetiva para o interior da consciência, pois esse processo é, ele próprio, criador da consciência.

Esses aspectos decorrem, portanto, da ação do sujeito associada às condições socioculturais e técnicas do meio, que é também mediação. As funções superiores originam-se das relações reais entre indivíduos. Por assim dizer, não são inventadas e não aparecem de forma repentina, pois não existem independentemente das experiências. São funções que apresentam uma natureza histórica de origem sociocultural. São, portanto, mediadas.

A mediação, para Vigotski (2010), não é uma possibilidade de facilitar o processo de ensino e aprendizagem. Segundo o autor, deve-se problematizar a reflexão para que se efetive a aprendizagem. Isso porque 
[...] ao criar o caminho mais fácil e cômodo para assimilar conhecimento, ao mesmo tempo paralisa na raiz o hábito do pensamento independente, tira da criança essa preocupação e afasta conscientemente da educação todos os momentos de elaboração complexa da experiência, exigindo que todo o necessário seja levado ao aluno em forma desmembrada, mastigada e digerida. Entretanto, é necessário que nos preocupemos precisamente com a criação do maior número possível de dificuldades na educação da criança como pontos de partida para os seus pensamentos (VIGOTSKI, 2010, p. 237-238).

Segundo esse posicionamento, o processo de ensino e aprendizagem realiza-se a partir de problemas, dificuldades, permitindo que os alunos se mobilizem para pensar, refletir e buscar respostas. Esse entendimento reforça a importância dos conhecimentos cotidianos para o ensino de Geografia, a fim de que se construa o conhecimento científico de forma mais significativa para o aluno.

Seguindo essa linha de raciocínio, o próximo item apresenta uma discussão sobre a relevância da formação de conceitos, visando a uma melhor compreensão da mediação didática para o ensino e aprendizagem em Geografia.

\section{A IMPORTÂNCIA DA MEDIAÇÃO DIDÁTICA PARA A APRENDIZAGEM GEOGRÁFICA}

Toda a discussão tecida até o momento tem respaldo nas orientações de Vigotski (1896-1934), precursor da Teoria Histórico-Cultural. Nesse sentido, busca-se, em sua vasta produção, aportes para a compreensão do desenvolvimento dos conhecimentos científicos e cotidianos. Visando a um embasamento teórico acerca desse estudo, em particular sobre a formação dos referidos conceitos, objetiva-se elencar a importância do desenvolvimento desses conceitos para o ensino de Geografia. A teoria elaborada sobre a formação de conceitos foi, sem dúvida, uma das maiores contribuições de Vigotski, dada a sua compreensão de realidade para além de sua dimensão concreta e imediata.

A formação de conceitos é resultado de um processo complexo, vasto e constante na formação de um indivíduo. É a partir deles (dos conceitos) que o homem adquire modos de operar o pensamento, suas ações mentais para compreender o mundo.

Segundo a pesquisa desenvolvida por Vigotski (2010), ao problematizar o tema do desenvolvimento dos conhecimentos científicos e cotidianos, produziu-se a premissa advinda do avanço de sua obra, que diz que o desenvolvimento do pensamento está ligado ao processo de aprendizagem, o que estava na contramão do que vinha sendo discutido até aquele momento na Psicologia. Para o autor, há dois aspectos, no estudo concreto do pensamento, que possuem importância na análise do processo de aprendizagem.

O primeiro aspecto diz respeito ao crescimento e desenvolvimento do próprio conceito, entendido, nesse primeiro momento, como sendo o significado da palavra absolutamente empírico e concreto. Trata-se da compreensão de que o desenvolvimento do pensamento é um processo interno profundo de mudança da estrutura do próprio significado da palavra. 
O segundo aspecto tem a ver com a própria afirmação de Vigotski (2010), quando assinala que o significado da palavra afigura-se como uma unidade sumamente importante de estudo do pensamento. Afinal, está na natureza da palavra o fato de ela ter certo significado e todo significado representa uma generalização, etapa imprescindível para o processo de aprendizagem.

O conceito tem uma história de desenvolvimento muito longa. Segundo Vigotski (2010), na criança ele se desenvolve muito antes do seu ingresso na escola. Com a iniciação escolar, no entanto, a criança passa a percorrer um caminho interessantíssimo e novo no desenvolvimento de seus conceitos.

Desse modo, com base no postulado vigotskiano, partilhamos do princípio de que não existe uma hierarquia entre conhecimentos científicos e cotidianos. Ao contrário, ambos podem ser estimulados pelo professor para a construção do conhecimento, pois estão ligados entre si, apesar das diferenças que os envolvem.

A investigação realizada por Vigotski (2010, p. 524) destaca que, a priori, havia a crença de que o caminho do desenvolvimento do conceito científico repetia basicamente o caminho do desenvolvimento dos conceitos cotidianos, ou seja, acreditava-se que o conceito surge com algumas variações na experiência cotidiana. E também de que o conceito "corriqueiro" (cotidiano) efetivamente transformava-se no conceito científico, era assimilado ou sugerido, ou seja, chegava "à cabeça da criança a despeito do desenvolvimento".

O autor refuga tais proposições afirmando que, na verdade, "os conceitos científicos se desenvolvem na criança de modo diferente do que se desenvolvem os espontâneos e por outras vias" (VIGOTSKI, 2010). Assim, tais conclusões servem de referência para a discussão proposta neste trabalho.

Os conceitos cotidianos desenvolvem-se com a ajuda dos adultos e do meio social, porque a aprendizagem não começa na idade escolar, do mesmo modo que o conceito científico não começa e não surge de algum campo desconhecido. Para exemplificar, Vigotski (2010, p. 525) destaca que, "se na aula a criança ouve falar de água ou gelo, antes ela já sabia alguma coisa a respeito". Assim, este estudo propõe tratar do conceito de lugar para além de sua condição empírica entre as diversas disciplinas escolares. Considera o lugar, antes de tudo, como elemento do raciocínio geográfico, que está presente no dia a dia dos alunos e, por isso, contribui para uma mediação didática desejável ao processo de ensino e aprendizagem em Geografia. Em outras palavras, entende-se, aqui, o lugar como um referencial teórico e cotidiano para a compreensão do pensamento espacial, como categoria que é uma dimensão da realidade. Por esse viés, o presente estudo está centrado no processo de ensino e aprendizagem no que respeita à construção de conceitos geográficos.

Para legitimar o argumento exposto, esta discussão encontra fundamento nos estudos de Cavalcanti (2012, p. 162), professora e pesquisadora na área do ensino de Geografia que vem trabalhando com as orientações vigotskianas há alguns anos. A referida autora afirma que o nível de abstração e generalização no processo de formação dos conceitos cotidianos é "ascendente", constituído a partir de experiências, mas de uma forma ainda não consciente, e "ascendendo" para um conceito conscientemente definido. Os conceitos científicos surgem de modo contrário, posto que seu movimento 
é "descendente". Inicia-se com uma definição verbal e aplicações não espontâneas e, posteriormente, adquire um nível de concretude, impregnando-se na experiência. Segundo Cavalcanti (2012), essas formulações são importantes quando o objetivo é a formação de conceitos no ensino, em razão da consideração de que dos conceitos cotidianos dos alunos e da ascensão deles ao nível dos conceitos científicos pode se constituir uma tarefa própria da mediação didática.

De acordo com as reflexões apresentadas por Cavalcanti (2012), as quais são embasadas em Vigotski $(2000,2007,2010)$, este texto busca analisar a categoria lugar como mediação didática peculiar ao processo de ensino e aprendizagem em Geografia. O objetivo, como já referido anteriormente, é a própria análise da mediação didática para a aprendizagem geográfica. Parte-se do pressuposto de que a categoria lugar, possuidora de características próprias do cotidiano e do espaço vivido dos sujeitos, pode ser considerada, para além de um referencial teórico, um conceito cotidiano capaz de dar maior significado aos conceitos científicos.

Não se pretende absolutizar as diferenças e/ou semelhanças entre os conceitos cotidianos e científicos, uma vez que há aspectos comuns entre eles no que se refere às vias de desenvolvimento desses conceitos. Persiste, contudo, o entendimento de que o desenvolvimento dos conceitos científicos segue o caminho oposto ao que segue o desenvolvimento do conhecimento cotidiano, conforme afirma Vigotski (2010). Como exemplo, cite-se a situação em que uma criança já conhece algo e formulou um conceito dele, mas ainda tem dificuldade de dizer o que representa esse conceito na sua totalidade. Vale lembrar que o conceito científico surge exatamente com a definição verbal, mediante operações a ela vinculadas. Apesar dessa contraposição, ambos os processos de desenvolvimento dos conceitos cotidianos e científicos estão internamente interligados da maneira mais profunda. Estão interligados, conforme conclui Vigotski (2010), por que o desenvolvimento dos conceitos cotidianos deve atingir certo nível para que a criança possa assimilar em linhas gerais os conceitos científicos.

Seria possível afirmar que, com o conhecimento cotidiano do espaço, vivido e experienciado, o aluno vai para a escola com uma série de saberes ou conhecimentos capazes de promover uma significativa construção dos conhecimentos científicos?

Acredita-se que essa resposta seja afirmativa, afinal, ao chegar à sala de aula, o aluno traz consigo uma série de saberes adquiridos em seu cotidiano, a partir de suas experiências diárias. A utilização dessa "bagagem" perpassa um interessante caminho metodológico, abrindo espaço para problematizações e questionamentos, com o nítido intuito de permitir que os alunos se mobilizem para pensar, refletir e buscar respostas. Esse entendimento reforça a importância dos conhecimentos cotidianos para o ensino de Geografia, a fim de que se construa o conhecimento científico de forma mais significativa para o aluno. Nesse sentido, o entendimento é o de que o processo de ensino e aprendizagem realiza-se a partir de problemas, dificuldades. Logo, pode-se firmar que esses dois tipos de conceitos não estão no mesmo nível de desenvolvimento. De acordo com Vigotski (2010, p. 538), "havendo os respectivos momentos programáticos no processo de educação, o desenvolvimento dos conceitos científicos supera o desenvolvimento dos espontâneos". É no campo dos conhecimentos científicos que se encontra o nível mais elevado de pensamento. 
E, assim, Vigotski (2010) se pergunta: O que ocorre na transformação dos conceitos espontâneos em científicos? Sua resposta é conclusiva:

[...] todo conceito científico deve apoiar-se em uma série de conceitos espontâneos que germinam até chegar à escola e transformá-los em científicos. Nos termos mais gerais, pode-se dizer que o conceito espontâneo se transforma em uma nova parte do seu desenvolvimento. A criança o conscientiza, ele se modifica na estrutura, ou seja, passa à generalização de um tipo mais elevado no aspecto funcional e revela a possibilidade das operações, dos signos que caracterizam a atividade do conceito científico (VIGOTSKI, 2010, p. 539-540).

Na linha de pensamento aqui adotada, defende-se que o conceito cotidiano pode e deve ser considerado no processo de ensino e aprendizagem, pois o jovem estudante possui em sua bagagem uma série de saberes capazes de germinar e de se transformar em conceitos científicos. Vale lembrar que os conceitos científicos apoiam-se em uma série de informações anteriormente adquiridas ou, até mesmo, em outros conceitos já assimilados. É inevitável, portanto, pensar o conceito de lugar no ensino de Geografia. E sua formação ocorre com a experiência fenomênica dos alunos, a partir de seus próprios locais da vida cotidiana.

O estudo do lugar, pensado como referência do conhecimento empírico, dos conceitos cotidianos, permite, inicialmente, a identificação e a compreensão da Geografia de cada um. A reflexão sobre o lugar, as implicações ou a significação desse lugar e a compreensão de que outros lugares são diferentes exigem que o aluno desenvolva determinados pensamentos espaciais e que tenha informações objetivas do seu e de outros lugares. Daí a importância da consideração dos conceitos cotidianos para o amadurecimento e transformação em conceitos científicos.

De acordo com esse entendimento, Cavalcanti (2012) propõe como meta para o ensino de Geografia o desenvolvimento de conceitos cognitivos por meio da ação mediativa. Para a assimilação dos conteúdos é necessária a formação de conceitos geográficos, compreendidos como as formas mais elaboradas do pensamento dessa ciência. A autora reafirma que a mediação da atividade cognitiva relaciona-se com a preocupação com o aluno, como sujeito ativo do processo de conhecimento, premissa presente nas atuais reflexões sobre o ensino de Geografia.

Por conseguinte, conclui-se que o aluno poderá, em um ensino que promova a formação de conceitos, adquirir recursos mentais que lhe permitam compreender o espaço geográfico a sua volta, sendo capaz de entender toda sua complexidade, seus conflitos e contradições a partir da análise de sua forma, de seu conteúdo e de sua historicidade. Cavalcanti (2012, p. 163) reitera que, "compreendendo seu lugar e os territórios formados em suas proximidades, como uma espacialidade, o aluno terá uma convicção de que aprender elementos do espaço é importante para compreender o mundo, pois ele é uma dimensão constitutiva da realidade".

Nessa perspectiva, o objetivo da Geografia escolar não está restrito à transmissão de conteúdo para informação do aluno. A finalidade do ensino de Geografia, nessa visão, é trabalhar esses conteúdos em prol do desenvolvimento de um modo de pensar e agir geográficos. É papel da escola e das aulas de Geografia formar um pensamento 
conceitual que permita uma mudança na interação do sujeito com o mundo, afinal, a aprendizagem é um importante instrumento mediador da relação desse sujeito com o mundo em que está inserido.

Em conformidade com as orientações de Vigotski, Cavalcanti (2012, p. 169) retoma a ideia de que "a formação de conceitos pressupõe encontro e confronto entre conceitos cotidianos e conceitos científicos". Isso direciona um olhar privilegiado para a Geografia cotidiana dos alunos, pois é no "encontro/confronto" dos saberes cotidianos com os saberes científicos que se tem a possibilidade de reelaboração e maior compreensão do espaço vivido. Conforme mencionado, as orientações vigotskianas têm ganhado espaço na reflexão sobre o ensino de Geografia. Assim como Cavalcanti, outros professores e pesquisadores têm se pautado nos aportes teóricos e metodológicos de Vigotski, como Couto (2006) e Richter (2011), por exemplo.

Couto (2006, p. 79) destaca que, embora não se ensinem conceitos diretamente, o aprendizado escolar permite desenvolver "as habilidades intelectuais que tornam consciente o próprio ato de pensar, como a atenção voluntária, a memória lógica, a capacidade de diferenciação, a classificação, a análise, a síntese, a abstração". Todos esses são elementos indispensáveis para a construção de conceitos. Nessa perspectiva, o autor retoma um fato importante da concepção vigotskiana: "Para iniciar o processo de formação de conceitos, é necessário confrontar o estudante com algum problema possível de ser resolvido com a aquisição de novos conceitos" (COUTO, 2006, p. 86). Assim, pode-se iniciar o processo de ensino e aprendizagem mediante uma tarefa ou problema que incentive a necessidade de introduzir novos conceitos em seu desenvolvimento, ou seja, que a solução do problema possa ser realizada de forma gradual. O autor reitera que, desse modo, para se constituir uma proposta pedagógica, o processo de construção de conceitos deve ter início com um desafio e contar com atividades que promovam a utilização dos recursos mediadores da percepção e da palavra por parte dos alunos.

No que se refere à palavra, de acordo com a teoria de Vigotski, vale ressaltar sua importância em relação direta com a linguagem, na formação dos conceitos. Entendida, segundo Richter (2011, p. 67), como "mediação pela qual os conceitos podem ser usados pelos indivíduos em suas interpretações a respeito do mundo em que vivem", a palavra tem uma função diferenciada. $O$ autor desdobra sua argumentação afirmando que o conhecimento produzido pelo ser humano encontra-se organizado em expressões que são conhecidas como palavras que, por sua vez, representam uma síntese na compreensão de determinado elemento do contexto social.

A palavra, assim como a linguagem, são signos (atividade interna) que combinados com as ferramentas (atividade externa) formam a atividade mediadora (capacidade de usar algo como mediação). Para este estudo é pertinente ressaltar a própria Geografia como instrumento simbólico na mediação do sujeito com o mundo, considerando que essa mediação envolve uma relação sujeito-objeto e que essa relação é contraditória. Em síntese, a mediação é o processo que promove a relação do homem com o mundo (Geografia) e outros homens, é um processo, em primeira instância, social, e os conceitos são construídos socialmente, para só então serem internalizados, modificados e aplicados na vida prática. 


\section{CONSIDERAÇÕES FINAIS}

Este estudo vem tratando da compreensão do conceito de mediação na Teoria Histórico-Cultural, pautando-se nos estudos vigotskianos. Destaca a importância da mediação didática para a aprendizagem geográfica. Busca-se uma melhor compreensão acerca dos indícios ou apontamentos que evidenciem as dificuldades e/ou facilidades na construção do conhecimento geográfico por meio de uma mediação didática desejável ao ensino de Geografia.

Diante do exposto, chama-se a atenção, em primeiro lugar, para as contribuições da mediação, utilizando-se, para isso, como referência, Tébar (2011). Esse autor destaca alguns critérios da mediação que interessam para esta pesquisa: intencionalidade e reciprocidade; significado; sentimento de capacidade; regulação e controle da conduta; conduta compartilhada; individualização e diferenciação psicológica; busca, planejamento e conquista de objetivos; mudança; conhecimento do ser humano como entidade mutável; busca de alternativas otimistas; sentimento de pertencimento a uma cultura.

A mediação tem como eixo central três critérios basilares: o significado; intencionalidade/reciprocidade e a aplicação (transcendência). Os outros critérios mencionados são resultado de um encaminhamento metodológico baseado nesses eixos norteadores e mediadores. Com base nesse entendimento, a utilização desses critérios reafirma o intuito de promover não uma aprendizagem associativa, e sim construtiva. Para isso, ressalta-se que o sujeito, aqui, é reconhecido como um ser dinâmico e produtivo, jamais estático e reprodutivo; a mudança e a transformação são internas, pois se acredita na tomada de consciência; a natureza da mudança deve ser qualitativa e não apenas quantitativa, e a aprendizagem pressupõe ressignificação e não associação pura.

O paradigma mediador promove uma mudança metodológica e essa mudança metodológica pode ser pautada em parâmetros para a ação educativa, como apresenta Tébar (2011, p. 223):

\section{$[\ldots]$}

- estar ciente dos conhecimentos prévios dos alunos e permitir que estes exerçam uma participação ativa, formulem perguntas e elaborem todo tipo de projeção com os novos conteúdos;

- dar oportunidade para os alunos exercitarem suas competências de forma autônoma. Deve haver plasticidade de intervenção diferenciada do professor, segundo as necessidades e os diferentes ritmos de aprendizagem dos alunos;

- criar um clima de confiança, segurança, afeto e respeito mútuos que propicie uma comunicação fácil e eficiente na sala de aula;

- organizar e planejar as sequências didáticas que permitam a previsão dos objetivos e meios para se alcançar as metas propostas;

- ajustar a estrutura de cada tarefa às possibilidades de cada aluno;

- observar e conhecer o processo que permita assegurar um alto nível de participação dos educandos. A construção pessoal da criança desponta no âmbito das relações sociais que ela estabelece com outras pessoas e, no caso da escola, com seus colegas e o professor. 
Nesse sentido, faz-se necessário ressaltar um conceito imprescindível para a elaboração deste trabalho - a "zona de desenvolvimento proximal" como base para o ensino - pautando-se na perspectiva vigotskiana.

A zona de desenvolvimento proximal é uma ferramenta analítica para avaliação do desenvolvimento dos alunos em conexão com a escolarização. "A zona de desenvolvimento proximal de Vigotski conecta uma perspectiva psicológica geral sobre o desenvolvimento da criança com uma perspectiva pedagógica com o ensino, [...] o desenvolvimento psicológico e o ensino são socialmente enquadrados" (HEDEGAARD, 2002, p. 199). Dentro de seus limites, as crianças são capazes de reproduzir ações que ultrapassam suas competências, por meio da imitação. Quando, no entanto, suas ações são acompanhadas e direcionadas por adultos, elas se saem muito melhor do que se deixadas sozinhas. É justamente nessa diferença entre o nível de tarefas resolvidas com a orientação de um adulto e o nível de tarefas resolvidas de modo independente pelas crianças e jovens que se encontra a zona de desenvolvimento proximal.

Ainda de acordo com a autora, a principal característica do ensino é que ele cria a zona de desenvolvimento proximal, estimulando uma série de processos internos de desenvolvimento, por isso este conceito é um instrumento necessário para o planejamento do ensino e explicação de seus resultados.

Esse entendimento leva a concluir que os conceitos cotidianos são desenvolvidos numa relação dialética com os conceitos científicos, que são mediados pelo ensino, pelo professor e outros instrumentos de mediação. Se os conceitos científicos, entretanto, não forem inseridos e confrontados com os cotidianos, todo o desenvolvimento da criança será afetado. Com isso, retoma-se a pergunta que norteia este estudo: De que modo o conceito de lugar contribui para uma mediação didática desejável para o processo de ensino e aprendizagem em Geografia?

O lugar, além de ser referência empírica das diversas disciplinas escolares, perpassa elementos do conhecimento cotidiano, do espaço vivido e experienciado. É elemento do raciocínio geográfico e, por isso, contribui para uma mediação didática desejável para o processo de ensino e aprendizagem em Geografia. O lugar, assim, é um referencial teórico para a construção de um pensamento espacial, uma categoria que é uma dimensão da realidade. E a mediação promove o encontro e o confronto entre conhecimentos científicos e conhecimentos cotidianos.

\section{REFERÊNCIAS}

CAVALCANTI, L. S. Cotidiano, mediação pedagógica e formação de conceitos: uma contribuição de Vygotsky ao ensino de Geografia. Caderno Cedes, v. 25, n. 66, maio/ago. 2005.

CAVALCANTI, L. S. O ensino de geografia na escola. Campinas, SP: Papirus, 2012. (Coleção magistério: formação e trabalho pedagógico).

COUTO, M. A. C. Pensar por conceitos geográficos. In: CASTELLAR, S. M. V. (org.). Educação geográfica: teorias e práticas docentes. Novas abordagens. Geousp. São Paulo: Contexto, 2006. V. 5.

HEDEGAARD, M. A zona de desenvolvimento proximal como base para o ensino. In: DANIELS, H. (org.). Uma introdução a Vygotsky. Tradução Marcos Bagno. São Paulo: Edições Loyola, 2002.

LIBÂNEO, J. C.; FREITAS, R. A. M. da M. Vygotsky, Leontiev, Davydov: três aportes teóricos para a teoria histórico-cultural e suas contribuições para a didática. In: CONGRESSO BRASILEIRO DE HISTÓRIA DA EDUCAÇÃO, 4., 2006. Goiânia. Anais [...]. Goiânia: Editora Vieira; UCG, 2006. 
LIBÂNEO, J. C. Docência universitária: formação do pensamento teórico-científico e atuação nos motivos dos alunos. In: D’ÁVILA, C. (org.). Ser professor na contemporaneidade: desafios, ludicidade e protagonismo. Curitiba: Editora CRV, 2009a.

LIBÂNEO, J. C. Teoria histórico-cultural e metodologia de ensino: para aprender a pensar geograficamente. In: ENCUENTRO DE GEÓGRAFOS DE AMÉRICA LATINA (EGAL), 12., 2009. Montevideo. Anais [...]. Montevideo, Uruguay: Universidad de la República, 2009b.

LIBÂNEO, J. C. Ensinar e aprender/aprender e ensinar: o lugar da teoria e da prática em didática. In: LIBÂNEO, J. C.; ALVES, N. (org.). Temas de pedagogia: diálogos entre didática e currículo. São Paulo: Cortez Editora, 2012.

RICHTER, D. O mapa mental no ensino de geografia: concepções e propostas para o trabalho docente. São Paulo: Cultura Acadêmica, 2011.

TÉBAR, L. O perfil do professor mediador: pedagogia da mediação. Tradução Priscila Pereira Mota. São Paulo: Editora Senac São Paulo, 2011.

VIGOTSKI, L. S. A formação social da mente. Tradução José Cipolla Neto, Luís Silveira M. Barreto e Solange C. Afeche. São Paulo: Martins Fontes, 2007.

VIGOTSKI, L. S. Obras escogidas III (Incluye problemas del desarrollo de la psique). Tradução Lydia Kuper. Madrid: Visor, 2000.

VIGOTSKI, L. S. Psicologia pedagógica. Tradução Paulo Bezerra. São Paulo: Martins Fontes, 2010. 